Michael J. Beckley

is Vice President, Lodging Development for Canada, Marriott International plc. He was founding Chairman of

Experience Canada, a partnership marketing

consortium promoting

Canada's tourism industry,

which has now evolved into the

Canadian Tourism

Commission. He was also Chairman of the Tourism Sectoral Strategy for the Province of Ontario, appointed by the Premier, and founding Chairman of the Ontario Tourism Council, appointed by the Minister for Trade and Tourism. In 1994 he was named Hotelier Magazine's 'Hotelier of the Year'.

Keywords:

hotels, development hot spots, Canada, tourism, occupancy rates

Michael J. Beckley

Vice President Lodging Development Marriott Hotels of Canada 10 Carlson Ct., Suite 640 Toronto, ON MgW 6L2

Canada

Tel: +1 4166797240

Fax: +1 4162138341

E-mail: michael.beckley@marriott.com

\section{Development opportunities in the Canadian hotel market}

\author{
Michael J. Beckley
}

Received (in revised form): 26 August 2002

\begin{abstract}
The Canadian hospitality market is underdeveloped and less overbuilt compared to its US counterpart and the combination of a growing economy, increased tourism, business spending and government initiatives presents impressive hotel development opportunities. This paper will examine why this is good news for hoteliers and the hospitality industry and why it is time for hotel investors to take a good hard look at Canada.
\end{abstract}

\section{THE CHALLENGES}

The National Post, one of Canada's premier national newspapers, ran an article in January of this year headlined, 'Canada seen as growing twice as fast as US.' The predicted growth in Canada is especially encouraging news given the challenges the hotel industry faced in 2001 - both before and after September 11. Financing for new development had not been easily available and the underwriting criteria were tightened at the first signs of recession in mid-2001. This trend became even more pronounced after the tragic events of September 11, which prompted many lenders to consider only requests below 50 per cent loan to value. Others have adjusted downward from the 60-65 per cent range to the 50-55 per cent range. ${ }^{2}$

In November 2001 hotel occupancy in Canada was down 2 per cent for the year to date over $2000 .{ }^{3}$ However, average rates were up almost $\$ 4$, leading to a slight increase in RevPar (revenue per available room). ${ }^{4}$ One-fifth of companies surveyed in the first quarter of 2002 said they would spend less on travel and overall expected travel by Americans remains soft but the leisure travel segment is showing gradual signs of improvement for late 2002 and into 2003. ${ }^{5}$

The key learning in all this is that in any challenging economic environment, especially in a relatively tight-knit market where most people know the major players, relationships are even more crucial to success. When financing is tight, lenders need to be sure they are dealing with a known commodity.

Lenders realise obvious benefits from partnering with a major brand over a smaller company. A proven brand has precedence and can demonstrate a consistent return on investment, thus giving lenders a much greater comfort level when faced with tight underwriting criteria and demands for proven performance levels. 


\section{Optimistic economic growth and tourism spending}

\section{THE GOOD NEWS}

But as the North American economy begins to correct, keep an eye on Canada, which is predicted to grow at more than twice the pace of the USA. This rebound is thanks in part to the fact that Canada never experienced the full-blown recession that affected the USA. In fact, Tim O'Neill, chief economist at the Bank of Montreal, told a lunch meeting of senior executives in Montreal in January that Canada's economic doldrums are merely a 'recessionette' from which Canada will emerge with a 'significant acceleration' in growth. ${ }^{6}$

Combine this economic growth prediction with increased tourism spending and Canada is looking even better. According to information from the Canadian Tourism Commission and the Conference Board of Canada, ${ }^{7}$ current forecasts include:

- domestic leisure travel is expected to increase by 3-4 per cent (currently 80 per cent of Canada's travel industry)

- eight out of ten Canadians will choose travel within Canada for their next overnight trip

- three out of ten Americans are more likely to consider travelling to Canada rather than going overseas (61 per cent prefer to stay closer to home after September 11).

More and more Americans seem to recognise that Canada is everything they want in a destination: exciting cities, diverse cultures and friendly people, pristine wilderness, incredible value, all in an environment that is viewed as a safe, close-to-home destination. Add to this the Open Skies Agreement which has opened more Canadian airports to direct flights from the USA, and, of course, the continuing strength of the US dollar compared to the Canadian dollar, typically about a 30 per cent value which certainly makes spending in Canada very attractive to Americans.

The economic recovery also bodes well for an upswing in business travel. Inventories are lower, consumer spending continues to increase, interest rates are lower than they have ever been and the housing market remains steady. According to a recent article by Ian Jack in the Financial Post reporting on a Statistics Canada survey of 27,000 businesses and institutions, 'the driving factors will be housing investment, up 11.9 per cent to 48.2 billion, and municipal spending on infrastructure, set to increase 27 per cent to 10.7 billion'. 8

Also impacting on Canada's recovery are major government initiatives designed to promote tourism further. The Canadian Tourism Commission's (CTC) new national marketing campaign to promote tourism in Canada ran from November 2001 to April 2002. Domestic travel and tourism received C\$8 million and another C\$12 million was spent to reach travellers in the USA. While the results are still to be tallied, the general impression is that the programme was a great success. 


\section{Good investments}

\section{Importance of relationships}

Moving forward, the CTC sees 2002 as a year of recovery, with the expectation that 2003 will be a year of change and 2004 will be a year of success. To that end, the CTC is currently receiving an annual contribution of $\mathrm{C} \$ 75.5 \mathrm{~m}$ per year as an operating budget, but an additional C $\$ 25 \mathrm{~m}$ from the federal government is being considered. This C\$100m annual operating budget will be earmarked for marketing to help sell Canada as a top-of-mind destination and provide the Canadian tourism industry with strategic information to facilitate and improve decision making.

\section{THE OPPORTUNITIES}

Given all the positive economic news coming from Canada, the hotel industry has some very specific opportunities in the form of distressed properties that one can refer to as 'tired product'. These are excellent opportunities for acquisitions, renovations and repositionings. Some examples include the Renaissance Toronto Hotel at Skydome, the Toronto Marriott Bloor Yorkville and the Ottawa Marriott. In each case, hotel companies look to properties that are structurally sound, have the potential for good market return, are compatible with the brand and are capable of giving 'lift' to the owner (usually through the benefit of a strong brand), as the key factors in determining whether a 'tired property' is a good investment. Additionally, the supply of new hotel rooms coming in to the market is falling and, while no hard numbers are available for 2002, the number is expected to fall again.

This trend in reduced supply will affect the consumer as one continues to see enormous potential for growth in tourism and travel. The Conference Board of Canada reports that domestic travel is rising steadily, and that in 2003 overnight domestic business will increase by 3.0 per cent. ${ }^{9}$ Additionally, domestic travel expenditures are expected to increase by 3.7 per cent before expanding a further 6.1 per cent in $2003 .{ }^{10}$ Consumer confidence is on the upswing and is currently at its highest level since 1988, according to the Consumer Confidence Index. ${ }^{11}$ The nation is safe and secure, and as travellers decide to stay closer to home and family, Canada is the obvious choice.

As for business travel, most analysts feel this sector will also recover due to the importance of relationships and human interaction in doing business. Alternative methods of conducting business such as videoconferencing, combined with stricter corporate travel policies, will mean a slower recovery but a resumption of normal business travel patterns is expected in 2003. As Marriott CEO Bill Marriott always says, 'the grease that makes business work is travel'. ${ }^{12}$ So there is confidence that business travel will soon return to the levels of before September 11. This is confirmed by the International Air Transport Association's recent corporate travel survey, which indicated that just under half of the respondents expect their business travel plans to return to normal within six months and 39 per cent indicated a return to normal 
levels within a year. ${ }^{13}$ As an aside, it is important to note that Canada's economy has been moving away from a pure commodity base to increased emphasis on an industrial, commercial, manufacturing and high-tech base. Because a diversified base is generally regarded as more recession proof, this scenario certainly has more positive implications for Canadian industry and business in general.

With encouraging travel projections for the remainder of $2002^{14}$ and beyond, and the optimism surrounding the growth in business travel along with the economy, Canada is clearly an attractive hotel investment opportunity for Americans and Canadians alike. On new builds, one looks for IRRs in the 20 per cent plus range, capitalisation rates at 10-12 per cent; equity is available and construction financing is available but take-out lending is still the main issue. Ironically, hotel companies have had more success with conduit lenders from south of the border than with Canadian lenders.

\section{BEST BETS IN CANADA}

Some specific market opportunities include Toronto, Montreal and Vancouver for high-end urban properties. The trend here is for mixed-use properties which include residential housing or connections to convention, trade and exhibition centres. An example of this is the Ritz Carlton mixed-use building including high-end condominiums in the city core, as predicted for Vancouver. Similarly, extended-stay products, such as Residence Inns and Marriott Executive Apartment Hotels, in an urban location, either as stand alone or again as part of mixed-use residential complexes, are making the most of the economies of operation.

\section{Room for expansion in Canada}

Opportunities also exist in major cities for brand infill. This is especially true in extended-stay properties and in the diversification of products such as Marriott's line of Residence Inns, Springhill Suites and the Renaissance and Courtyard brands. One way to understand this statement better is to look to the cities of Atlanta, Georgia and Toronto, Ontario for comparison. Both have similar population numbers but Atlanta has 80 Marriott-branded properties alone, whereas Toronto has 11 .

Because the hotel industry in general in Canada is underpenetrated, there are enormous opportunities in mid-market areas - these include hotels in smaller towns and suburbs where a large, full-service four-star property is probably not required. Barrie, Ontario and Lethbridge, Alberta, with populations of around 50,000-100,000, are good examples. The average rate for rooms in these hotels would be approximately C\$75-100 as opposed to C\$150-200, with few exceptions. ${ }^{15}$

The targeted total cost should be C\$110-120 per room including land, financing costs and furniture, fixtures and equipment (FF\&E) with a targeted, stabilised occupancy of 70 per cent. The key to 


\section{Resort development opportunities}

maximising ROE is the ability to leverage up to 70 per cent debt financing. The typical Marriott Courtyard and Residence Inn hotels are able to achieve gross operating profit margins well above industry norms, given the design efficiencies and minimal food and beverage and meeting rooms.

Coast to coast, opportunities abound as communities from the Maritimes in the east to Edmonton, Calgary and Vancouver in western Canada continue to develop their industrial, commercial and tourism sectors. Hotels which fare best in these markets include full service for the meeting and restaurant business, limited service for the sleeping and transient business, and extended-stay properties.

Canada is well known for its magnificent skiing and natural beauty. Yet many of the country's best-known resort areas, such as Banff, Kelowna and Whistler in the Canadian Rockies and Mont Tremblant and northern Ontario, have untapped hotel opportunities. It is important to remember that while growth in traditional ski areas such as Banff and Whistler is limited, new areas are being developed. These include Big White and Silver Star in British Columbia, Canmore in Alberta, Blue Mountain in Ontario and Mont Tremblant. Additionally, given the growth of ecotourism, Canada's appeal is no longer just about the vertical slope.

It is already known that additional supply in Canada can create additional demand. Niagara Falls has had and continues to have the largest hotel growth in Canada. ${ }^{16}$ As the city grows, demand has kept pace with this growth, proving that where tourism infrastructure increases, demand follows.

As a case in point, a March 2001 article in Canadian Lodging Outlook reaffirms this statement with facts. ${ }^{17}$ Niagara Falls, Canada:

- currently has approximately 11,000 rooms with over half of these rooms representing the mid-size to larger chain-affiliated motels and hotels

- occupied room nights have increased by 27 per cent while supply only grew by 13 per cent over the past four years

- the average daily rate (ADR) in 1996 was C\$84.09, while in 2000 the ADR was C $\$ 120.36$ - an increase of 43 per cent.

New, upscale hotels by Marriott (including the first spa in Canada), Sheraton and Hilton appeal to the upscale traveller and prove that there is a segment of demand not previously being met.

Additionally, the creation of Casino Niagara has raised the profile of the market as a multi-dimensional destination.

This growth in demand and the ensuing diversity of supply has taken Niagara Falls from a small, independent owner-operated hospitality market to Canada's sixth largest accommodation market behind Toronto, Montreal, Vancouver, Ottawa and Calgary, respectively. ${ }^{18}$ 


\section{Soft dollar, strong market}

\section{DOLLARS AND SENSE}

The opportunities for acquisitions, repositionings and strong brand affiliation are good. Property capitalisation rates are still reasonable in Canada, which means this is a good time to invest. The market is open and older, 'tired' products are ripe to be replaced with vibrant new hotels and newly renovated properties.

Additionally, the average rate differential in Canada has diminished from years past with larger brands attracting a greater proportion of US traffic. This coincides with operators demonstrating greater rate integrity to translate into increased RevPar. RevPar, an important profitability indicator in the hospitality and hotel business, continues to climb from a Canadian average of C\$72 in 2000 to C\$74 in 2001 and a projection of C\$76 for 2003, according to a report by Pannell, Kerr, Forster Consulting. ${ }^{19}$

Canada makes a great deal of sense for the American and international investor. The benefits of a rapidly improving economy, fiscal and monetary stimuli programmes, real value, huge development potential and an increased government commitment to funding tourism will resonate with investors - especially the US investor. It is definitely time for hotel investors to take a good, hard look at this vibrant hotel industry north of the border.

\section{References}

1. Vieira, P. (2002) National Post, 3rd January.

2. INNvestment CANADA, Colliers International Hotels, company newsletter, First Quarter 2002.

3. Pannell, Kerr, Forster Consulting (2002) Trends in the Canadian Hotel Industry, May, found at www.pkfcanada.com.

4. Ibid.

5. The Conference Board of Canada (2002) Travel Markets Outlook 2002, Winter Update, found at www.conferenceboard.ca.

6. National Post (2002) 'Dollar defenders hit New York: martin, Dodge to build on campaign's early success with Wall St. speeches, full-page ads', 30th January.

7. Ibid.; Canadian Tourism Research Institute (2002) International Travel Forecasts 2002, First Quarter Update, March.

8. Jack, I. (2002) Financial Post, 25th July.

9. The Conference Board of Canada, ref. 5 above.

10. Ibid.

11. The Conference Board of Canada, Consumer Research Center, found at www.conferenceboard.ca.

12. Marriott, B. (2001) Washington Post, 5th October.

13. International Air Transport Association (2001) Corporate Air Travel Survey 2001 Edition.

14. The Conference Board of Canada, ref. 5 above.

15. Canadian Lodging Outlook, Hospitality Valuation Services International, Smith Travel Research, December 2001, found at www.hvsinternational.com.

16. Lantz, J. (2001) 'HVS International - Toronto', Canadian Lodging Outlook, March, found at www.hvsinternational.com.

17. Ibid.

18. Ibid.

19. Pannell, Kerr, Forster Consulting, ref. 3 above. 